\title{
On Fejér type inclusions for products of interval-valued convex functions
}

\author{
Hasan KARA ${ }^{1}$, Hüseyin BUDAK ${ }^{2}$, and Samet ERDEN ${ }^{3}$ \\ ${ }^{1}$ Düzce Üniversitesi \\ ${ }^{2}$ Düzce University \\ ${ }^{3}$ Bartin University Faculty of Sciences
}

September 27, 2020

\begin{abstract}
We first get some new Fejér type inclusions for products of interval-valued convex mappings. The most important feature of our work is that it contains Fejér type inclusions for both interval-valued integrals and interval-valued fractional integrals.
\end{abstract}

\section{Hosted file}

On Fej\selectlanguage\{ngerman\}ér type inclusions for products of interval-valued convex functions.pdf available at https://authorea.com/users/360953/articles/483455-on-fej\%C3\%A9r-type-

inclusions-for-products-of-interval-valued-convex-functions 